\title{
Neurofibromatosis 2 [Bilateral acoustic neurofibromatosis, central neurofibromatosis, NF2, neurofibromatosis type II]
}

\author{
D. Gareth R. Evans, MD, FRCP
}

TABLE OF CONTENTS

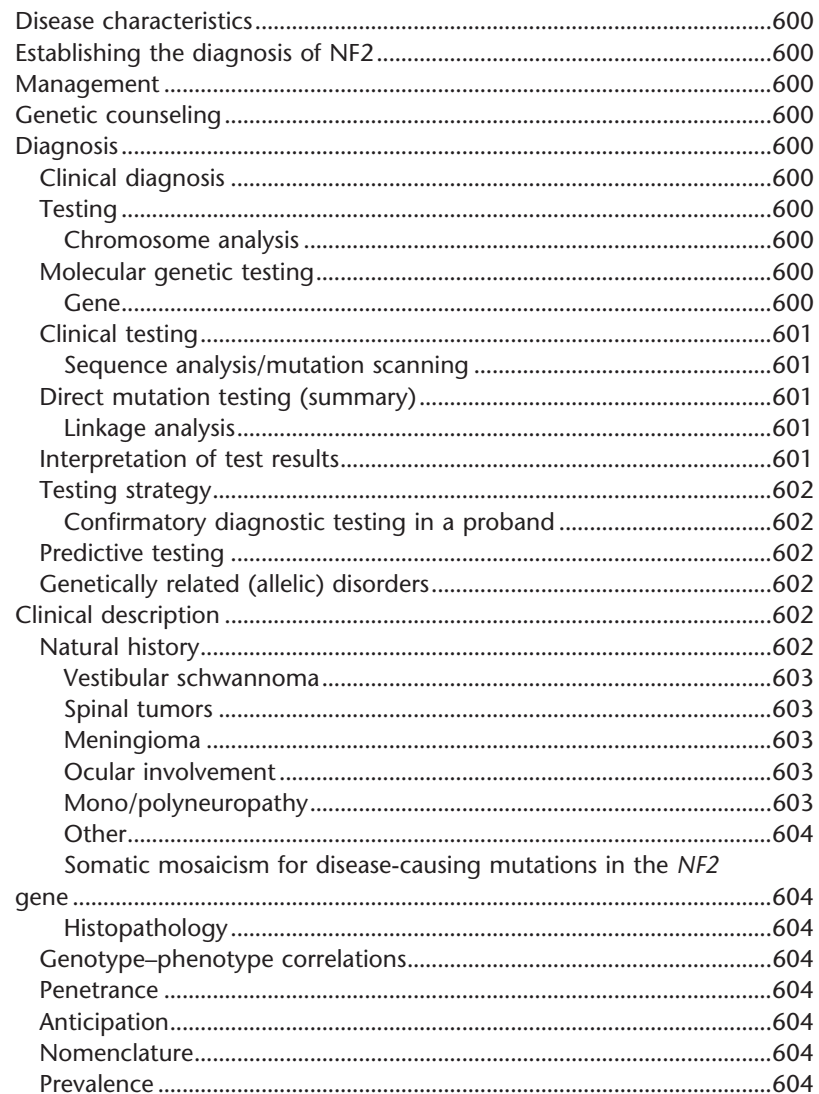

Abstract: Neurofibromatosis 2 is a dominantly inherited tumor predisposition syndrome caused by mutations in the NF2 gene on chromosome 22. Affected individuals inevitably develop schwannomas typically affecting both vestibular nerves leading to deafness. Rehabilitation with brainstem implants is improving this outcome. Schwannomas also occur on other cranial nerves, on spinal nerve roots, and on peripheral nerves. Meningiomas and ependymomas are other tumor features. In excess of $50 \%$ of patients represent new mutations and as many as one third are mosaic for the underlying disease causing mutation. Although truncating mutations (nonsense and frameshifts) are the most frequent

From the Medical Genetics Research Group, Regional Genetics Service and National Molecular Genetics Reference Laboratory, Manchester University and Central Manchester Foundation Trust, St Mary's Hospital, Manchester, United Kingdom.

D. Gareth R. Evans, MD, FRCP, Department of Medical Genetics, St Mary's Hospital, Hathersage Road, Manchester M13 0JH, United Kingdom. E-mail: gareth.evans@cmft.nhs.uk.

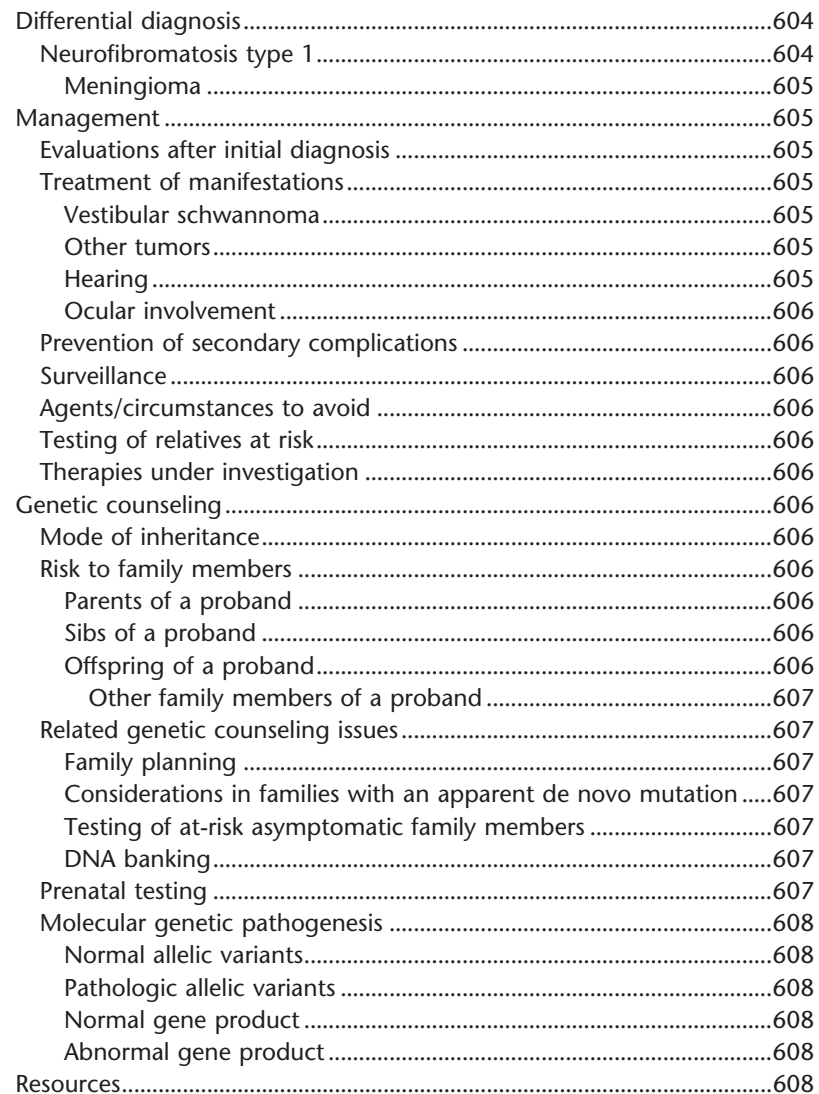

germline event and cause the most severe disease, single and multiple exon deletions are common. A strategy for detection of the latter is vital for a sensitive analysis. NF2 represents a difficult management problem with most patients facing substantial morbidity and reduced life expectancy. Surgery remains the focus of current management, although watchful waiting and occasionally radiation treatment have a role. In the future, the development of tailored drug therapies aimed at the genetic level are likely to provide huge improvements for this devastating, life limiting condition. Genet Med 2009:11(9):599-610.

Key Words: NF2, vestibular schwannoma, meningioma, ependymoma

Disclosure: The author declares no conflict of interest

Submitted for publication March 21, 2009

Accepted for publication May 1, 2009

Published online ahead of print July 31, 2009

DOI: 10.1097/GIM.0b013e3181ac9a27 


\section{DISEASE CHARACTERISTICS}

Neurofibromatosis 2 (NF2) is characterized by bilateral vestibular schwannomas with associated symptoms of tinnitus, hearing loss, and balance dysfunction. ${ }^{1}$ The average age of onset is 18 to 24 years. ${ }^{1}$ Almost all affected individuals develop bilateral vestibular schwannomas by the age of 30 years. ${ }^{1}$ Affected individuals may also develop schwannomas of other cranial and peripheral nerves, meningiomas, and, rarely, ependymomas and astrocytomas. Posterior subcapsular lens opacities that rarely progress to a visually significant cataract are the most common ocular findings and may be the first sign of NF2. Mononeuropathy that occurs in childhood is an increasingly recognized finding; it frequently presents as a persistent facial palsy, a squint (third nerve palsy), or hand/foot drop. ${ }^{2}$

\section{ESTABLISHING THE DIAGNOSIS OF NF2}

Diagnosis of NF2 is based on clinical criteria (Table 1). ${ }^{1,3}$ $N F 2$ is the only gene known to be associated with NF2. Molecular genetic testing of NF2 that includes a combination of sequence analysis or mutation scanning and duplication/deletion testing detects a mutation in most affected individuals who have a positive family history and are not the first individual in the family known to have the disorder. Identification of a pathogenic NF2 mutation in blood or in two separate tumors from the same individual confirms the diagnosis.

\section{MANAGEMENT}

Treatment of manifestations: Treatment of vestibular schwannoma is primarily surgical; stereotactic radiosurgery, most commonly with the gamma knife, may be an alternative to surgery. Individuals with vestibular tumors need to be aware of insidious problems with balance and underwater disorientation, which can result in drowning. ${ }^{1,4}$ Treatment for hearing loss includes referral to an audiologist, lip-reading and sign language instruction, and possibly hearing aids and/or cochlear or brainstem implants.

Surveillance: For affected or at-risk individuals, annual magnetic resonance imaging (MRI) beginning at the age of approx-

Table 1 Diagnostic criteria for NF2 (these include the $\mathrm{NIH}$ criteria with additional criteria)

Bilateral vestibular schwannomas

A first-degree relative with NF2 AND

Unilateral vestibular schwannoma

OR

Any two of: meningioma, schwannoma, glioma, neurofibroma, posterior subcapsular lenticular opacities ${ }^{a}$

Unilateral vestibular schwannoma AND any two of: meningioma, schwannoma, glioma, neurofibroma, posterior subcapsular lenticular opacities ${ }^{a}$

Multiple meningiomas AND

Unilateral vestibular schwannoma

OR

Any two of: schwannoma, glioma, neurofibroma, cataract a"Any two of" = two individual tumors or cataract. imately 10 to 12 years and continuing until at least the fourth decade of life and hearing evaluation, including auditory brainstem evoked response testing..$^{5,6}$

Agents/circumstances to avoid: Radiation therapy of NF2associated tumors, especially in childhood, may induce, accelerate, or transform tumors.

Testing of relatives at risk: Early identification of relatives who have inherited the family-specific NF2 mutation allows for appropriate surveillance, resulting in earlier detection and treatment of disease manifestations.

\section{GENETIC COUNSELING}

NF2 is inherited in an autosomal dominant manner. Nearly $50 \%$ of individuals with NF2 have an affected parent, and a little $>50 \%$ have NF2 as the result of a de novo mutation ${ }^{7-9}$ (unpublished data). However, $25 \%$ to $33 \%$ of simplex cases (i.e., single occurrence in a family) are mosaic for an NF2 mutation. ${ }^{10-12}$ If the proband has other affected family members, each child of the proband has a $50 \%$ chance of inheriting the mutation. Prenatal testing for pregnancies at increased risk is possible if the family-specific disease-causing mutation is known or linkage has been established in the family.

\section{DIAGNOSIS}

\section{Clinical diagnosis}

Modifications to the original National Institutes of Health consensus diagnostic criteria ${ }^{13}$ for NF2 have been suggested ${ }^{1,14}$ to enable earlier diagnosis of a founder (i.e., the individual in the first generation of a family known to be affected). These clinical diagnostic criteria for NF2 particularly the Manchester criteria $^{1}$ have been found to improve sensitivity substantially without affecting specificity. ${ }^{3}$ According to the modified criteria, NF2 is diagnosed in individuals fulfilling the criteria in Table 1.

\section{Testing}

\section{Chromosome analysis}

A variety of chromosome abnormalities can be associated with NF2:

- Cytogenetically visible deletions encompassing the NF2 gene may cause mental retardation and can cause congenital abnormalities. ${ }^{15}$ Smaller deletions that remove multiple exons of the NF2 gene or the whole gene can also be identified by fluorescence in situ hybridization analysis. ${ }^{16}$

- Ring chromosome 22 can also cause multiple meningiomas and vestibular schwannomas fulfilling NF2 diagnostic criteria. ${ }^{16}$ The NF2 locus itself is usually present within the ring, but the ring itself is frequently lost as a result of instability.

- Apparently balanced chromosomal translocations that disrupt the NF2 gene have also been described as causing NF2. ${ }^{16}$

Note: Gross chromosomal changes detectable on normal cytogenetic analysis are fairly uncommon.

\section{Molecular genetic testing \\ Gene}

$N F 2$ is the only gene known to be associated with NF2. It was identified through family linkage and tumor testing. ${ }^{17-21}$ 


\section{Clinical testing}

\section{Sequence analysis/mutation scanning}

The mutation detection rate in leukocyte DNA depends on which generation in a family is tested and whether the family history is positive or negative, i.e., the individual being tested represents a simplex case (i.e., a single occurrence in a family).

- In 101 of $108(93 \%)$ of families with NF2, sequence analysis identified a mutation in a member of the second generation $^{12}$ (unpublished study).

- In simplex cases, the mutation detection rate is around $60 \% .^{12}$

- About $25 \%$ to $33 \%$ of mutations are not detected as a result of somatic mosaicism. ${ }^{10-12,22}$ These usually require access to tumor material although mosaicism levels of $>10 \%$ can be detected in lymphocyte DNA. ${ }^{12}$

Deletion/duplication analysis that systematically detects whole exon deletions and duplications suggests that at least $10 \%$ to $15 \%$ of $N F 2$ constitutional aberrations are deletions ranging in size of 10 to $600 \mathrm{~kb}^{23-25}$ These deletions are not associated with mental retardation, even if quite large. Note: Most large deletions and, less commonly, duplications of single exons or multiple exons can be detected by multiplex-ligation dependent probe amplification (MLPA). ${ }^{24,25}$ The results of testing 529 families in Manchester are presented in Tables 2 and 3.

\section{Direct mutation testing (summary)}

1. Mutation detection rates are lower in simplex cases, and in the person in the first generation of a family to have NF2 because they are more likely to have somatic mosaicism.

2. Testing that detects deletions/duplications not readily detectable by sequence analysis of genomic DNA; a variety of methods may be used such as quantitative polymerase chain reaction, real-time polymerase chain reaction, MLPA, or array comparative genomic hybridization.

3. When mutation scanning is combined with deletion/duplication analysis of single exons, the mutation detection rate approaches $72 \%$ in simplex cases and exceeds $92 \%$ for familial cases. ${ }^{3,24}$ Other studies have reported lower mutation detection rates, which may reflect the inclusion of some more mildly affected individuals with somatic mosaicism.

\section{Linkage analysis}

Linkage analysis can be considered in families in whom no disease-causing mutation is identified and at least two family members of different generations are affected. Linkage studies are based on an accurate clinical diagnosis of NF2 in the affected family members and accurate understanding of genetic relationships in the family. Linkage analysis depends on the availability and willingness of the family members to be tested. The markers used for linkage analysis of NF2 are highly informative and very tightly linked to the NF2 gene; thus, they can be used in more than $95 \%$ of families with NF2 with $>99 \%$ accuracy. Linkage testing is not available to families with a single affected individual, a situation that often occurs when an individual has a de novo gene mutation and no affected offspring. However, a modified linkage analysis using constitutional and tumor DNA can exclude NF2 in at least half of the children of a simplex case if they can be shown to have inherited the allele lost in the tumor. ${ }^{10,12,26}$
Table 2 MLPA abnormalities in 62 unrelated families from 529 tested

\begin{tabular}{lc}
\hline MLPA abnormality & No. occasions (mosaic) \\
\hline $\begin{array}{l}\text { Exon 1-intron 1 (deletes intronic } \\
\text { CA repeat) }\end{array}$ & $18(3)$ \\
Whole gene (exons 1-17) & $16(2)$ \\
$\quad$ deletion & $3(2)$ \\
Exons $5-17$ deletion & 2 \\
Exons 2-3 deletion & 2 \\
Exons 2-10 deletion & 1 \\
Exons $13-15$ deletion & $2(1)$ \\
Exons $1-16$ deletion & $3(1)$ \\
Exons $1-10$ deletion & 1 \\
Exons $1-3$ deletion & $2(1)$ \\
Exons $1-4$ deletion & $1(1)$ \\
Exons $1-2$ deletion & 1 \\
Exons $15-17$ deletion & 1 \\
Exons $8-17$ deletion & 1 \\
Exons $8-15$ deletion & 1 \\
Exon 3 deletion & 1 \\
Exon 7 deletion & 1 \\
Exon 5 deletion & 1 \\
Exons $12-14$ duplication & 1 \\
Exons $10-16$ duplication & 1 \\
Exon 8 deletion & 1 \\
\hline &
\end{tabular}

\section{Interpretation of test results}

- Most mutations in NF2 found on sequence analysis are pathogenic. Some missense mutations or in-frame deletions may be harmless and need interpreting in the light of previous research, ${ }^{27-29}$ the impact on protein structure and from species conservation.

- Research has shown that as many as $25 \%$ to $33 \%$ of individuals with NF2 caused by a de novo mutation have somatic mosaic for the mutation. ${ }^{10-12,22}$ Recognition of individuals who have somatic mosaicism for an NF2 disease-causing mutation can be problematic because these individuals:

May not have bilateral vestibular schwannomas. ${ }^{30}$

May have normal molecular genetic testing of the NF2 gene in unaffected tissue, such as lymphocytes; thus, molecular genetic testing of tumor tissue may be necessary to establish the presence of somatic mosaicism. $3,10-12,22,31,32$

- A parent can be excluded as having NF2 if his/her offspring is shown to have somatic mosaicism for an NF2 mutation. Conversely, absence of an NF2 mutation de- 
Table 3 Mutations identified in 529 families with NF2 in the Manchester (UK) genetics laboratory

\begin{tabular}{|c|c|c|c|c|}
\hline Type of mutation & $\begin{array}{l}\text { Detection in second } \\
\text { generation }(\mathrm{n}=108)\end{array}$ & $\begin{array}{l}\text { Detection in sporadic nonmosaic } \\
\text { patients }(\% \text { nonmosaic })^{a}\end{array}$ & $\begin{array}{l}\text { Mosaic mutations } \\
(\% \text { of mosaic })\end{array}$ & Total \\
\hline Splice site & $35(32)$ & $43(22)$ & $3(4)$ & $80(15)$ \\
\hline MLPA positive & $23(20)$ & $28(14)$ & $11(15)$ & $62(12)$ \\
\hline FSD & $18(17)$ & $36(18)$ & $20(26)$ & $74(13)$ \\
\hline Nonsense & $16(15)$ & $67(35)$ & $28(37)$ & $111(22)$ \\
\hline Missense & $7(6)$ & $5(3)$ & $1(1)$ & $13(2.5)$ \\
\hline FSI & $3(3)$ & $11(7)$ & $6(8)$ & $20(4)$ \\
\hline IFD & $1(1)$ & 1 & $3(4)$ & $5(1)$ \\
\hline Ring 22 & 0 & 0 & $3(4)$ & 3 \\
\hline Not found & $7(7)$ & $230(55)$ & 158 & $166 / 529(31)$ \\
\hline Total & 108 & $191 / 421(45)$ & 72 & 529 \\
\hline
\end{tabular}

The values within parentheses represent percentages.

${ }^{a}$ Including mosaic patients detected in blood leukocyte DNA 227 of 241 (54\%) simplex cases were detectable on blood analysis.

FSD, frame shift deletion; FSI, frame shift insertion; IFD, inframe deletion.

tected in all cells of an offspring does not eliminate the possibility of somatic mosaicism for an NF2 mutation in the parent and absence of a mutation in leukocyte DNA of an affected de novo case does not exclude mosaicism in either parent or offspring.

\section{Testing strategy}

\section{Confirmatory diagnostic testing in a proband}

One of two sample types is used ideally this should be:

- Leukocyte DNA from an affected individual who has an affected parent;

- Tumor DNA from an individual who is a simplex case.

Molecular genetic testing is performed in the following order:

1. Testing for large deletions using a technique such as MLPA;

2. Sequence analysis of exons 1 to 15 (mutations have never been described in exons 16-17).

When tumor DNA is tested, mutations in both NF2 alleles must be identified:

- This may mean testing for loss (or inactivation) of one $N F 2$ allele by assessing for loss of heterozygosity (LOH).

- Once both NF2 mutant alleles are identified in the tumor, leukocyte DNA can be tested to determine which one of the mutations is constitutional and which is somatic (present in the tumor only).

\section{Predictive testing}

- At-risk relatives whose genetic status is unknown can be tested for the presence of the NF2 mutation (either constitutional or somatic mosaic) identified in an affected relative such as the proband.

- In the rare instance in which an NF2 mutation cannot be identified, linkage analysis can be used in families with at least two affected family members of different generations or tumor DNA can be used to exclude at least half of children as being at risk.

- Offspring of a simplex case in whom molecular genetic testing of a tumor has revealed $\mathrm{LOH}$ can be reassured if testing of their leukocyte DNA shows that they have inherited the allele that was lost in the parental tumor, because this allele is unlikely to have a disease-causing mutation. 3,26

Prenatal diagnosis/preimplantation genetic diagnosis for atrisk pregnancies require prior identification of the diseasecausing mutation in the family.

\section{Genetically related (allelic) disorders}

No other phenotypes are known to be associated with mutations in the NF2 gene.

\section{CLINICAL DESCRIPTION}

\section{Natural history}

The average age of onset of findings in individuals with NF2 is 18 to 24 years. The age of onset ranges from birth to 70 years. ${ }^{1,2,4,33,34}$ Almost all affected individuals develop bilateral vestibular schwannomas by the age of 30 years. ${ }^{5}$ In addition to vestibular schwannoma, individuals with NF2 develop schwannomas of other cranial and peripheral nerves, meningiomas, ependymomas and, very rarely astrocytomas. The clinical characteristics from four major studies are presented in Table 4.

Variable expressivity of NF2 among individuals results in varying size, location, and number of tumors. Although these tumors are not malignant, their anatomic location and multiplicity lead to great morbidity and early mortality. The average age of death is 36 years. Actuarial survival from the time of establishing the correct diagnosis was 15 years in patients presenting in the 1970 s to 1980 s. $^{1,7,8}$ Survival is improving with earlier diagnosis and better treatment in specialty centers. 6,35

Because NF2 is considered an adult-onset disease, it may be underrecognized in children, in whom skin tumors and ocular findings may be the first manifestations..$^{2,36}$ 
Table 4 Clinical characteristics of NF2 patients in four studies

\begin{tabular}{|c|c|c|c|c|}
\hline \multirow[b]{2}{*}{ Characteristic } & \multicolumn{4}{|c|}{ Study } \\
\hline & Kanter et al. ${ }^{4}$ & Evans et al. ${ }^{1}$ & Parry et al. ${ }^{33}$ & Mautner et al. ${ }^{34}$ \\
\hline No. cases & 73 & 120 & 63 & 48 \\
\hline No. families & 17 & 75 & 32 & 44 \\
\hline Sporadic cases & 0 & 45 & 17 & 44 \\
\hline Mean age at onset (yr) & $20(59)$ & 22 & 20 & 17 \\
\hline Intracranial meningiomas (\%) & 18 & 45 & 49 & 58 \\
\hline Spinal tumors $(\%)$ & NA & 26 & 67 & 90 \\
\hline Skin tumor $(\%) \mathrm{s}$ & $32(73)$ & $68(100)$ & 67 & 64 \\
\hline$>10$ skin tumors $(\%)$ & NA & $10(100)$ & NA & NA \\
\hline Café-au-lait macules (\%) & $42(31)$ & $43(100)$ & 47 & NA \\
\hline Cataract (\%) & NA & $38(90)$ & 81 & 62 \\
\hline Intracranial astrocytoma (\%) & NA & 4.1 & 1.6 & NA \\
\hline Ependymoma (\%) & NA & 2.5 & 3.2 & 6 \\
\hline Optic sheath meningioma $(\%)^{a}$ & NA & 4.1 & 4.8 & 8 \\
\hline
\end{tabular}

\section{Vestibular schwannoma}

Initial symptoms include tinnitus, hearing loss, and balance dysfunction. Onset of disability is usually insidious, although occasionally hearing loss may occur suddenly, presumably as a result of vascular compromise by the tumor. Affected individuals often report difficulty in using the telephone in one ear or unsteadiness when walking at night or on uneven ground.

With time, vestibular tumors extend medially into the cerebellar pontine angle and, if left untreated, cause compression of the brainstem and hydrocephalus. Significant facial palsy is rare even in large tumors. However, surgical management of large tumors particularly in inexperienced hands often ends in facial palsy. ${ }^{6}$

Schwannomas may also develop on other cranial and peripheral nerves, with sensory nerves more frequently affected than motor nerves. ${ }^{1}$

\section{Spinal tumors}

At least two thirds of individuals with NF2 develop spinal tumors, which are often the most devastating and difficult to manage. ${ }^{33,34,37,38}$ The most common spinal tumors are schwannomas, which usually originate within the intravertebral canal on the dorsal root and extend both medially and laterally, taking the shape of a "dumbbell." Intramedullary tumors of the spinal cord, such as ependymoma, occur in $5 \%$ to $33 \%$ of individuals with NF2. Most persons with spinal cord involvement have multiple tumors. Although multiple tumors are often present on imaging studies, they remain asymptomatic in many individuals.

\section{Meningioma}

Approximately half of individuals with NF2 in patient series have meningiomas. ${ }^{1,33,34}$ However, lifetime risk is likely to approach $75 \%$. Most are intracranial; however, spinal meningiomas occur. NF2 meningiomas tend to occur less frequently in the skull base than supratentorially and are usually of the fibroblastic variety. ${ }^{39,40}$ Meningiomas in the orbit may compress the optic nerve and result in visual loss. Those at the skull base may cause cranial neuropathy, brainstem compression, and hydrocephalus. Meningioma may be the presenting feature of NF2, particularly in childhood. , $^{41}$

\section{Ocular involvement}

One third of individuals with NF2 have decreased visual acuity in one or both eyes. ${ }^{42}$ Posterior subcapsular lens opacity rarely progressing to a visually significant cataract is the most common ocular finding. Lens opacities may appear before the onset of symptoms from vestibular schwannoma and can be seen in children. Retinal hamartoma and epiretinal membrane are seen in up to one third of individuals. Intracranial and intraorbital tumors may result in decreased visual acuity and diplopia. Rarely, other ocular manifestations may occur; persistent hyperplastic primary vitreous has been reported in a father and a son. ${ }^{43}$

Intracranial and intraorbital tumors may result in decreased visual acuity and diplopia.

\section{Mono/polyneuropathy}

An increasingly recognized feature of NF2 is a mononeuropathy occurring particularly in childhood ${ }^{2,36}$ and frequently presenting as a facial palsy that usually only partially recovers, a squint (third nerve palsy), or a foot or hand drop. The foot drop may mimic polio.

A progressive polyneuropathy of adulthood not directly related to tumor masses is also being increasingly recognized. ${ }^{1,44}$

Further evidence for the mononeuropathy of childhood and the polyneuropathy of adulthood has come from sural nerve biopsies. ${ }^{45}$ 


\section{Other}

Renal vascular disease similar to that occurring in NF1 has been reported once. ${ }^{46}$

\section{Somatic mosaicism for disease-causing mutations in the NF2 gene}

Mosaicism has been suspected in individuals with unilateral vestibular schwannoma and multiple other often ipsilateral tumors. ${ }^{10-12,22}$ This has now been confirmed for most cases in which DNA from multiple tumors has been analyzed. ${ }^{10-12,30,31}$

\section{Histopathology}

The tumors of NF2 are derived from Schwann cells, meningeal cells, and glial cells. They are uniformly benign. About $40 \%$ of NF2 vestibular tumors have a lobular pattern that is uncommon in tumors from individuals who have no known family history of NF2. ${ }^{47}$

- NF2-associated vestibular schwannomas tend to be more invasive and to have a higher degree of dividing cells than non-NF2 tumors. They also tend to be multifocal.

- NF2-associated meningiomas have a higher degree of dividing cells than non-NF2 meningiomas. NF2 meningiomas are usually of the fibroblastic variety.

- No histologic differences have been observed between glial tumors in individuals with NF2 and individuals who do not have NF2.

\section{Genotype-phenotype correlations}

Intrafamilial variability is much lower than interfamilial variability, suggesting a strong effect of the underlying genotype on the resulting phenotype.

Unlike NF1, large deletions of the NF2 gene have been associated with a mild phenotype. ${ }^{48}$

Nonsense and frame-shifting mutations have been associated with severe disease regardless of their positions within the gene. ${ }^{48-52}$

Splice site mutations have been associated with both mild and severe disease $e^{49,51,53}$ and may be milder if occurring in the $3^{\prime}$ half of the gene. ${ }^{54}$

Missense mutations are usually mild, often causing the mildest form of NF2.35,52

In general, truncating mutations (frameshift and nonsense) show a significantly more severe pattern of tumors and are associated with greater disease-related mortality than missense splice site and large deletions. ${ }^{35,48}$ Truncating mutations are also associated with increased prevalence of spinal tumors. ${ }^{37,38}$ Although most of these mutations would be predicted to result in nonsense-mediated decay, and, thus no protein product the apparent dominant negative effect of these requires further investigation.

Somatic mosaicism for typical truncating mutations (even when detectable in lymphocyte DNA) that would normally cause severe NF2 may also mitigate the effect, resulting in a milder phenotype. ${ }^{12,22}$ The type of $N F 2$ constitutional mutation is an important determinant of the number of NF2-associated intracranial meningiomas, spinal tumors, and peripheral nerve tumors. ${ }^{35}$ Again constitutional truncating mutations are associated with earlier onset and greater number of these tumors.

\section{Penetrance}

Penetrance is $100 \%$. All individuals who have a pathogenic mutation develop the disease in an average lifetime. Age at onset can vary with mutation type, as described earlier in the "Genotype-phenotype correlations" section.

\section{Anticipation}

Although some reports suggested anticipation in NF2, ${ }^{4}$ it is likely that these were instances of milder disease associated with mosaicism for an $N F 2$ mutation in the first generation and more severe disease associated with an $N F 2$ germline mutation in the second and subsequent generations. ${ }^{1}$

\section{Nomenclature}

The term "neurofibromatosis" is a misnomer, because the primary tumor types in NF2 are schwannoma and meningioma. Vestibular schwannoma (previously termed acoustic neuroma) was initially considered part of von Recklinghausen NF1, leading to multiple instances in which individuals with NF2 were included in series of individuals with NF1.

Since 1987, the great majority of reports have correctly distinguished between NF1 and NF2, with NF2 described as "bilateral acoustic" or "central" neurofibromatosis.

\section{Prevalence}

The incidence of NF2 was initially reported as 1:33,000 to 40,000 individuals. ${ }^{7}$ Disease prevalence was somewhat lower at $1: 210,000 .^{7}$ However, a recent update suggests that the incidence may be as high as 1:25,000; and the prevalence is now much higher at 1:80,000.9 The only other population-based study of NF2 in a smaller Finnish population found an incidence of 1 in 87,410 in a 1.7 million population. ${ }^{55}$ NF2 has no ethnic or racial predilections.

\section{DIFFERENTIAL DIAGNOSIS}

\section{Neurofibromatosis type 1}

Although they are clinically distinct and are caused by mutations in different genes at different chromosomal loci, diagnostic confusion continues to exist between NF1 and NF2; thus, it is worth noting several features that distinguish them:

- Individuals with NF2 do not have the cognitive problems (mental retardation and learning disability) seen in some individuals with NF1, nor do they have significant numbers of Lisch nodules (i.e., iris hamartomas).

- In individuals with NF2, schwannomas rarely, if ever, undergo malignant transformation to neurofibrosarcoma.

- Individuals with NF2, contrary to a common misconception, do not have significant numbers of café au lait macules, although they are probably more numerous than in the general population.

- The dumbbell configuration of the spinal root tumors, which are schwannomas in NF2 and neurofibromas in NF1, may occasionally cause initial diagnostic confusion between the two disorders.

Unilateral vestibular schwannoma is a common tumor in the general population, accounting for $5 \%$ to $10 \%$ of all intracranial tumors and the majority of cerebellar pontine angle tumors.

Around $5 \%$ of vestibular schwannomas are bilateral, ${ }^{9}$ and, thus associated with NF2; 95\% are unilateral occurrences in individuals who have no underlying genetic predisposition to such tumors. The risk that a unilateral tumor is the first manifestation of NF2 is closely related to the age of the affected individual.

- Individuals younger than 30 years, with a symptomatic unilateral vestibular schwannoma, are at high risk for developing a contralateral tumor and NF2 and should be monitored closely. Indeed, about $6 \%$ of individuals with an 
apparently isolated vestibular schwannoma are mosaic for an $N F 2$ gene mutation. ${ }^{31,32}$

- Individuals older than 30 years, with a unilateral vestibular schwannoma, have a negligible risk of developing NF2. ${ }^{32,56}$

The offspring of individuals with unilateral vestibular schwannoma and no known family history of schwannomas do not have an increased incidence of either NF2 or unilateral vestibular schwannoma. Somatic involvement of the NF2 gene in isolated vestibular schwannomas is almost universal ${ }^{31,57}$; however, the possibility exists that mutations in other genes on Chromosome 22 predispose to schwannoma development. $\mathrm{Mu}-$ tations in INII (SMARCB1) result in schwannomatosis ${ }^{56}$ and there are likely to be further genes that cause schwannomatosis and that could modify NF2.58

Schwannomatosis is defined as multiple schwannomas without the vestibular schwannomas that are diagnostic of NF2. ${ }^{59}$ Previous terminology for this condition has included multiple neurilemomas, multiple schwannomas, and neurilemomatosis. ${ }^{59}$

Individuals with schwannomatosis may develop intracranial, spinal nerve root, or peripheral nerve tumors; malignant transformation may rarely occur. One third of individuals with schwannomatosis have anatomically localized tumors suggestive of segmental disease. ${ }^{59}$

Familial cases seem to be inherited in an autosomal dominant manner, with highly variable expressivity and incomplete penetrance. Schwannomatosis is clinically and genetically distinct from NF1 and NF2, although some individuals with multiple schwannomas eventually fulfill NF2 diagnostic criteria and some individuals representing simplex cases with schwannomatosis are mosaic for an NF2 mutation. ${ }^{11,31,60}$ The locus for schwannomatosis had been mapped to an area close to, but excluding, the NF2 gene. ${ }^{61}$ A mutation in INI1 (SMARCB1) was identified in a schwannomatosis family. ${ }^{57}$ Subsequent analysis has shown that these cause $30 \%$ to $60 \%$ of familial schwannomatosis, but only a minority of sporadic disease. ${ }^{58,61,62}$

\section{Meningioma}

Rare instances of multiple meningiomas without vestibular schwannoma segregating as an autosomal dominant disorder have been reported. ${ }^{63}$ Linkage analysis of one affected family has implicated a locus distinct from the $N F 2$ locus. ${ }^{64}$ A gene other than NF2 is implicated in more than $60 \%$ of all meningiomas that occur in individuals with no known family history of meningiomas. ${ }^{65}$

Multiple meningiomas typically occur in older adults; thus, the finding of a single meningioma in an individual younger than 25 years should prompt an evaluation for an underlying genetic condition..$^{40}$ Meningiomas may predate the development of vestibular schwannomas, and any childhood meningioma should be considered as a possible early sign of NF2. 2,40,41 Individuals with multiple meningiomas may occasionally be mosaic for an NF2 mutation without the presence of vestibular schwannoma; but, in general, adults with multiple meningiomas and no vestibular schwannoma are at low risk for NF2. ${ }^{40}$

\section{MANAGEMENT}

\section{Evaluations after initial diagnosis}

To establish the extent of disease in an individual diagnosed with NF2, the following evaluations are recommended:

- Head MRI,
- Hearing evaluation, including brainstem auditory evoked response (BAER),

- Ophthalmologic evaluation, and

- Cutaneous examination.

Note: Evaluation and treatment of individuals with NF2 are best undertaken in an NF2 center experienced in managing the multiple complications of the disease. ${ }^{6,35}$

\section{Treatment of manifestations}

\section{Vestibular schwannoma}

Untreated tumors may be slow growing and not require active intervention in the short term. 6,66,67 Therapy remains primarily surgical. Small vestibular tumors $(<1.5 \mathrm{~mm})$ that are completely intercanalicular can often be completely resected, with preservation of both hearing and facial nerve function. Larger tumors are probably best managed expectantly, with debulking or decompression carried out only when brainstem compression, deterioration of hearing, and/or facial nerve dysfunction occur. ${ }^{6}$

Stereotactic radiosurgery, most commonly with the gamma knife, has been offered as an alternative to surgery in selected individuals with vestibular schwannoma. ${ }^{68}$ However, the outcomes from radiation treatment in individuals with NF2 are not as good as for individuals with sporadic unilateral vestibular schwannoma, with only approximately 60\% long-term tumor control. 69

Malignant transformation is a possible, but probably not common, sequelum ${ }^{70-72}$; however, it should be noted that tumor development after radiation may take 15 years. ${ }^{71}$ Reports of malignant transformation and new primary malignancies are also more common in NF2 than in the more frequently treated sporadic tumors. ${ }^{71,72}$ Fourteen of 20 reports of malignancy were in the context of NF2. ${ }^{72}$

Management of individuals with vestibular tumors should include counseling for insidious problems with balance and underwater disorientation, which can result in drowning. ${ }^{1,4}$

\section{Other tumors}

Other intracranial, cranial nerve, or spinal nerve tumors are very slow growing, and surgical intervention for a tumor producing little impairment may cause disability years before it would occur naturally.

Although ependymoma in individuals without NF2 is optimally treated with complete resection, and occasionally with radiotherapy and chemotherapy, it is unclear whether ependymoma in individuals with NF2 warrants aggressive management.

Radiation therapy of NF2-associated tumors should be carefully considered because radiation exposure may induce, accelerate, or transform tumors in an individual with an inactive tumor suppressor gene, especially a child..$^{70,71}$

\section{Hearing}

Hearing preservation and augmentation are important in the management of individuals with NF2. All affected individuals and their families should be referred to an audiologist, to receive training in optimization of hearing and speech production. Hearing aids may be helpful early in the course of the disease. ${ }^{6}$ Auditory rehabilitation with a cochlear or brainstem implant should be discussed with those who have lost hearing. ${ }^{6}$

Rarely, individuals who have had vascular insult to the cochlea, but otherwise are without nerve damage, may benefit from a cochlear implant. Lip-reading skills may be enhanced by 
instruction, and sign language may often be more effectively acquired before the individual loses hearing.

\section{Ocular involvement}

Early recognition and management of visual impairment from other manifestations of NF2 are extremely important.

\section{Prevention of secondary complications}

Prevention of substantial handicap from the disease can be achieved by appropriate expert treatment of tumors:

- A cervical spinal scan should be performed before cranial surgery, to prevent complications from manipulation under anesthesia. ${ }^{6}$

- Spinal tumors may make epidural analgesia difficult; therefore, lumbosacral imaging should be performed before regional analgesia is given. ${ }^{73,74}$

\section{Surveillance}

For at-risk individuals who have either tested positive for the known disease-causing mutation in their families or whose genetic status cannot be clarified by molecular genetic testing:

- MRI is usually begun between 10 and 12 years but can be delayed in families in which the onset is known to be later. ${ }^{6}$ MRI should be continued on an annual basis until at least the fourth decade of life. It is not clear if earlier surveillance (cranial MRI $<10$ years) is beneficial, and it is not known at what age monitoring can be safely stopped. Although some individuals with NF2 do not have symptoms until they are in their age of 50 years, it is likely that "silent" tumors would be detected on an MRI performed at a younger age.

- Hearing evaluation, including BAER testing, may be useful in detecting changes in auditory nerve function before changes can be visualized by MRI.

Routine complete eye examinations should be part of the care of all individuals with NF2. Cataracts can be present at birth and amblyopia is common in the formative years. ${ }^{1,2,36,75}$ In adulthood, there can be particular problems with the cornea especially after surgery that results in the loss of facial, trigeminal, and intermedius nerve function.

\section{Agents/circumstances to avoid}

Radiotherapy should be avoided in children with NF2. ${ }^{70}$

\section{Testing of relatives at risk}

Consideration of molecular genetic testing of at-risk family during childhood is appropriate for surveillance:

- Early identification of relatives who have inherited the family-specific NF2 mutation allows for appropriate screening using MRI for neuroimaging and BAER testing for audiologic evaluation, thus resulting in earlier detection of disease manifestations and improved final outcomes. . $^{5,6}$

- Early identification of those who have not inherited the family-specific NF2 mutation eliminates the need for costly screening with MRI and BAER testing.

\section{Therapies under investigation}

The search for an effective medical treatment for NF2-related tumors continues. One of the first agents suggested were PAK-1 blocking drugs. ${ }^{76}$ Targeting the ERK1, AKT, integrin/focal adhesion kinase/Src/Ras signaling cascades, PDGFR-beta, phosphatidylinositol 3-kinase/protein kinase C/Src/c-Raf path- way, VEG-F and other pathways ${ }^{77,78}$ means that drugs such as avastin, erlotinib, ${ }^{79}$ lapatinib, and sorafenib ${ }^{80}$ may well bear fruit. These agents could be tried on the NF2 mouse model in the first instance, but the first human clinical trials in North America and the United Kingdom are commencing.

Search ClinicalTrials.gov for access to information on clinical studies for a wide range of diseases and conditions.

Genetics clinics are a source of information for individuals and families regarding the natural history, treatment, mode of inheritance, and genetic risks to other family members as well as information about available consumer-oriented resources. See the GeneTests Clinic Directory.

Support groups have been established for individuals and families to provide information, support, and contact with other affected individuals.

\section{GENETIC COUNSELING}

\section{Mode of inheritance}

NF2 is inherited in an autosomal dominant manner.

\section{Risk to family members}

\section{Parents of a proband}

- About $50 \%$ of individuals with NF2 have an affected parent, and $50 \%$ have NF2 as the result of a de novo mutation. ${ }^{1,7,33}$ However, $25 \%$ to $33 \%$ of individuals who are simplex cases (i.e., individuals with no family history of NF2) are mosaic for an NF2 mutation. ${ }^{10-12}$

- Recommendations for the evaluation of parents of a proband with an apparent de novo mutation include a clinical history and, if any suspicion of NF2 exists, an MRI scan. A parent can be excluded as having NF2 if his/her offspring is shown to be mosaic, but absence of a mutation detected in the child does not eliminate the possibility of mosaicism in the parent. Because the age of onset of symptoms is consistent within families, it is usually not necessary to offer surveillance to asymptomatic parents.

\section{Sibs of a proband}

- The risk to the sibs of the proband depends on the genetic status of the parents.

- If a parent of the proband is affected, the risk to the sibs is $50 \%$.

- If neither parent of an individual with NF2 is symptomatic, the risk to the sibs of the affected individual is extremely low because the age of onset of symptoms is relatively uniform within families.

- However, a single case of germline mosaicism in a clinically normal individual has been reported. ${ }^{33}$

- Risks in various situations taking into account age of onset and laterality of presentation as well as molecular testing of a simplex case are presented in Table 5.

\section{Offspring of a proband}

Each child of an individual with NF2 has up to a $50 \%$ chance of inheriting the mutation:

- If the proband has other affected family members, each child of the proband has a $50 \%$ chance of inheriting the mutation.

- If the proband is the only affected individual in the family, two possibilities exist:

- The proband may have somatic mosaicism for the diseasecausing mutation. Offspring of an individual who is mo- 
Table 5 Transmission risks to offspring for isolated cases of NF2 before and after negative mutation testing

\begin{tabular}{|c|c|c|c|c|c|}
\hline & $\begin{array}{l}\text { No. individuals who } \\
\text { have generated } \\
\text { figures }\end{array}$ & $\begin{array}{l}\text { Pregenetic testing } \\
\text { mosaic inferred }^{a} \\
(\%)\end{array}$ & $\begin{array}{l}\text { Pregenetic testing } \\
\text { transmission risk } \\
\text { to offspring (\%) }\end{array}$ & $\begin{array}{l}\text { Postgenetic negative } \\
\text { testing in blood } \\
\text { mosaic inferred }^{b}(\%)\end{array}$ & $\begin{array}{l}\text { Postgenetic negative testing } \\
\text { in blood transmission risk } \\
\text { to offspring }\end{array}$ \\
\hline$<20$ BVS & 85 & 12 & 45 & 46 & $30 \% 1$ in 3 \\
\hline$<20$ UVS & 21 & 42 & 33 & 87 & $11 \% 1$ in 9 \\
\hline 20-29 BVS & 67 & 27 & 36 & 78 & $16 \% 1$ in 6 \\
\hline 20-29 UVS & 27 & 78 & 19 & 97 & $8 \% 1$ in 12 \\
\hline 30-39 BVS & 54 & 50 & 28 & 88 & $11 \% 1$ in 9 \\
\hline 30-39 UVS & 19 & 85 & 12 & 98 & $6 \% 1$ in 16 \\
\hline $40+$ BVS & 53 & 63 & 22 & 93 & $9 \% 1$ in 11 \\
\hline $40+$ UVS & 34 & 90 & 10 & 99 & $5 \% 1$ in 20 \\
\hline
\end{tabular}

Results are based on outcomes of testing in first affected (de novo) family members and on age at onset and laterality of presentation with VS.

${ }^{a}$ The chances that an individual will be mosaic based on age at presentation and laterality of VS presentation before undertaking genetic testing.

${ }^{b}$ The chances that an individual will be mosaic based on age at presentation and laterality of VS presentation after undertaking negative genetic testing in leukocyte DNA. VS, vestibular schwannoma; BVS, presentation with bilateral VS; UVS, initial presentation with unilateral VS.

saic will have less than a $50 \%$ risk of inheriting the disease-causing mutation. The proband may have a de novo germline mutation (i.e., present in the egg or sperm at the time of conception). Each offspring of an individual with a de novo germline mutation has a $50 \%$ chance of inheriting the mutation.

- Persons with somatic mosaicism and bilateral vestibular tumors have less than a $50 \%$ chance of having an affected child. ${ }^{10-12}$ If a point mutation is detected in DNA from multiple tumors, but not in DNA from leukocytes, the risk to offspring is probably $<5 \% .{ }^{12}$

Other family members of a proband. The risk to other family members depends on the genetic status of the proband's parents. If a parent is found to be affected, his or her family members may be at risk depending on the family structure.

\section{Related genetic counseling issues}

See the "Testing of relatives at risk" section for information on testing at-risk relatives for the purpose of early diagnosis and treatment.

\section{Family planning}

The optimal time for determination of genetic risk and discussion of the availability of prenatal testing is before pregnancy. Similarly, decisions about testing to determine the genetic status of at-risk asymptomatic family members are best made before pregnancy. It is appropriate to offer genetic counseling (including discussion of potential risks to offspring and reproductive options) to young adults who are affected or at risk.

\section{Considerations in families with an apparent de novo mutation}

When the parents of a proband with an autosomal dominant condition are unaffected, possible nonmedical explanations include alternate paternity or maternity (e.g., with assisted reproduction) or undisclosed adoption.

\section{Testing of at-risk asymptomatic family members}

Consideration of molecular genetic testing of at-risk family members during childhood is appropriate for surveillance. Mo- lecular genetic testing used in early identification of at-risk family members may be either mutation analysis or linkage analysis. Mutation analysis can only be used for testing of at-risk relatives if a disease-causing mutation has been identified in an affected family member. Linkage analysis is the preferred method of testing in families with more than one affected family member.

Because early detection of at-risk individuals affects medical management, testing of at-risk asymptomatic individuals who are younger than 18 years is beneficial. Parents often want to know the genetic status of their children before initiating screening, to avoid unnecessary procedures for a child who has not inherited the altered gene. Special consideration should be given to education of the children and their parents before genetic testing. A plan should be established for the manner in which results are to be given to the parents and children.

\section{DNA banking}

DNA banking is the storage of DNA (typically extracted from white blood cells) for possible future use. Because it is likely that testing methodology and our understanding of genes, mutations, and diseases will improve in the future, consideration should be given to banking DNA of affected individuals. DNA banking is particularly relevant in situations in which the sensitivity of currently available testing is $<100 \%$ or when linkage analysis is used.

\section{Prenatal testing}

Prenatal diagnosis of pregnancies at $50 \%$ risk for NF2 is possible by analysis of DNA extracted from fetal cells obtained by amniocentesis usually performed at about 15 to 18 weeks' gestation or chorionic villous sampling at about 10 to 12 weeks' gestation. The disease-causing allele of an affected family member must be identified or linkage established in the family before prenatal testing can be performed.

Preimplantation genetic diagnosis (PGD) may be available for families in which the disease-causing mutation has been identified. For laboratories offering PGD, see http:/www.ncbi.nlm.nih.gov/ bookshelf/br.fcgi?book= gene\&part $=$ nf 2 . 


\section{Molecular genetic pathogenesis}

\section{Normal allelic variants}

The NF2 gene spans $110 \mathrm{~kb}$ and comprises 16 constitutive exons and one alternatively spliced exon. $N F 2$ is widely expressed producing mRNAs in three different lengths of approximately 7, 4.4, and $2.6 \mathrm{~kb}$. No frequent normal allelic variants, even in codon wobble positions, have been reported in the NF2 gene.

\section{Pathologic allelic variants}

At least 200 different mutations in the $N F 2$ gene have been described, the majority of which are point mutations. ${ }^{27-29}$

A wide variety of mutations have been identified in all NF2 exons, except for the alternatively spliced exons 16 and 17. Ninety percent of the point mutations are predicted to truncate the protein by the introduction of a premature stop codon, a frameshift with premature termination, or a splicing alteration supporting the view that loss of the protein's normal function is necessary for the development of tumors. $\mathrm{C}$ to $\mathrm{T}$ transitions in CGA codons causing nonsense mutations are an especially frequent occurrence. ${ }^{81}$ Fewer than $10 \%$ of detected mutations involve in-frame deletions and missense mutations, which may indicate that alteration of particular functional domains can abolish the $N F 2$ tumor suppressor activity. ${ }^{28}$

Functional inactivation of the normal copy of NF2 can occur by a loss of chromosome 22 or a deletion of the long arm including the $N F 2$ gene. ${ }^{82}$ This mechanism of LOH leaves only one mutated copy of the $N F 2$ gene. A different mechanism of $\mathrm{LOH}$ is now recognized to be common with mitotic recombination. ${ }^{82}$ This results in two identically mutated copies of the NF2 gene. Somatic mutations are a common cause of abrogation of the second allele and there is a shift from nonsense mutations to frameshift mutations as the patient ages. ${ }^{82}$ Methylation is also now recognized as a cause of loss of function of the second allele. ${ }^{83,84}$

\section{Normal gene product}

The NF2 protein product has been named "merlin" (for moezin-ezrin-radixin-like protein) because of the high homology to the 4.1 family of cytoskeletal-associated proteins. Alternatively, the name schwannomin has been proposed in recognition of its role in preventing schwannoma formation. All 4.1 family members have a homologous domain of approximately 270 amino acids at the N terminus. In the NF2 protein and its close relatives, this domain is followed by a long alpha helical segment and a charged C-terminal domain. Protein 4.1, the best studied member of the family, plays a critical role in maintaining membrane stability and cell shape in the erythrocyte by connecting integral membrane proteins, glycophorin, and anion channel to the spectrin-actin lattice of the cytoskeleton. Protein 4.1 is the only other family member in which disease-causing mutations are known (hereditary elliptocytosis). Two major alternative forms of the NF2 protein product exist. Isoform 1 is a protein of 595 amino acids produced from exons 1 through 15 and exon 17. Presence of the alternatively spliced exon 16 alters the $\mathrm{C}$ terminus of the protein, replacing 16 amino acids with 11 novel residues in isoform 2. Additional alternative splices predicting other minor species have also been described.

Although the complete function of the NF2 protein remains elusive, recent studies suggest that merlin may coordinate the processes of growth-factor receptor signaling and cell adhesion. Varying use of this organizing activity by different types of cells could provide an explanation for the unique spectrum of tumors associated with NF2 deficiency in mammals. ${ }^{85}$

\section{Abnormal gene product}

Abnormal NF2 protein is caused by somatic and constitutional mutation. Attempts to identify truncated protein product have been unsuccessful in the main, although the nontruncated product from missense mutations may have partial function. It is thought that nonsense-mediated decay may account for the lack of identifiable product from most mutational types; however, this does not explain why phenotypes are more severe for this type of mutation than whole gene deletions.

\section{RESOURCES}

The Children's Tumor Foundation: Ending Neurofibromatosis Through Research

95 Pine Street, 16th Floor

New York, NY 10005

Phone: 800-323-7938; 212-344-6633

Fax: 212-747-0004

Email: info@ctf.org

www.ctf.org

National Library of Medicine Genetics Home Reference

Neurofibromatosis 2

NCBI Genes and Disease

Neurofibromatosis 2

Neurofibromatosis, Inc

PO Box 18246

Minneapolis, MN 55418

Phone: 800-942-6825; 301-918-4600

Fax: 301-918-0009

Email: info@nfinc.org

www.nfinc.org

The NF2 Review c/o the House of Ear Institute

2100 West Third Street Second Floor

Los Angeles, CA 90057

Phone: 213-483-4431

Fax: 213-413-0950

Email: jpetito@gateway.net

NF2 Sharing Network

10074 Cabachon Court

Ellicott City, MD 21042

Phone: 410-461-5213

Acoustic Neuroma Association

600 Peachtree Parkway Suite 108

Cumming, GA 30041-8211

Phone: 770-205-8211

Fax: 770-205-0239

Email: info@anausa.org

www.anausa.org

The UK Neurofibromatosis Association Quayside House 38 High Street, Kingston upon Thames

KT1 1HL

Surrey, United Kingdom

Phone: +44 2084391234

Fax: +442084391200

Email: nfa@zetnet.co.uk www.nfauk.org

\section{ACKNOWLEDGMENTS}

I thank Mia MacCollin, MD, Harvard Medical School, for her work on NF2 and authoring of the NF2 Gene review (1998-2004) and my colleagues Michael Baser and Andrew 
Shenton who both undertook great research on NF2 and died tragically young.

Professor D. Gareth Evans is supported by the NIHR Biomedical Research Centre at Central Manchester University Hospitals Foundation Trust.

\section{REFERENCES}

1. Evans DGR, Huson S, Donnai D, et al. Clinical study of type 2 neurofibromatosis. Q J Med 1992;84:603-618.

2. Evans DGR, Ramsden R, Birch J. Paediatric presentation of type 2 neurofibromatosis. Arch Dis Child 1999;81:496-499.

3. Baser ME, Friedman JM, Wallace AJ, Ramsden RT, Joe H, Evans DGR. Evaluation of diagnostic criteria for neurofibromatosis 2. Neurology 2002; 59:1759-1765

4. Kanter WR, Eldridge R, Fabricant R, Allen JC, Koerber T. Central neurofibromatosis with bilateral acoustic neuroma: genetic, clinical and biochemical distinctions from peripheral neurofibromatosis. Neurology 1980;30: $851-859$.

5. Evans DGR, Newton V, Neary W, et al. Use of MRI and audiological tests in pre-symptomatic diagnosis of type 2 neurofibromatosis (NF2). J Med Genet 2000;37:944-947.

6. Evans DGR, Baser ME, O'Reilly B, et al. Management of the patient and family with Neurofibromatosis 2: a consensus conference statement. $\mathrm{Br} J$ Neurosurg 2005;19:5-12

7. Evans DGR, Huson SM, Donnai D, et al. A genetic study of type 2 neurofibromatosis in the north west of England and the UK: I. prevalence, mutation rate, fitness and confirmation of maternal transmission effect on severity. J Med Genet 1992;29:841-846.

8. Evans DGR, Huson SM, Donnai D, et al. A genetic study of type 2 neurofibromatosis: II guidelines for genetic counselling. J Med Genet 1992; 29:846-852

9. Evans DGR, Moran A, King A, Saeed S, Gurusinghe N, Ramsden R. Incidence of vestibular schwannoma and neurofibromatosis 2 in the north west of England over a 10 year period: higher incidence than previously thought. Otol Neurotol 2005;26:93-97.

10. Kluwe L, Mautner VF, Heinrich B, et al. Molecular study of frequency of mosaicism in neurofibromatosis 2 patients with bilateral vestibular schwannomas. $J$ Med Genet 2003;40:109-114

11. Moyhuddin A, Baser ME, Watson C, et al. Somatic mosaicism in neurofibromatosis 2: prevalence and risk of disease transmission to offspring. $J$ Med Genet 2003;40:459-463.

12. Evans DGR, Ramsden RT, Shenton A, et al. Mosaicism in NF2 an update of risk based on uni/bilaterality of vestibular schwannoma at presentation and sensitive mutation analysis including MLPA. J Med Genet 2007;44:424-428.

13. National Institutes of Health Consensus Development Conference Statement on Neurofibromatosis. Arch Neurol 1987;45:575-579.

14. Gutmann DH, Aylsworth A, Carey JC, et al. The diagnostic evaluation and multidisciplinary management of neurofibromatosis 1 and neurofibromatosis 2. JAMA 1997;278:51-57.

15. Barbi G, Rossier E, Vossbeck S, et al. Constitutional de novo interstitial deletion of $8 \mathrm{Mb}$ on chromosome 22q12.1-12.3 encompassing the neurofibromatosis type 2 (NF2) locus in a dysmorphic girl with severe malformations. J Med Genet 2002;39:E6.

16. Tsilchorozidou T, Menko FH, Lalloo F, et al. Constitutional rearrangements of chromosome 22 as a cause of neurofibromatosis 2. J Med Genet 2004; 41:529-534.

17. Seizinger BR, Rouleau GA, Ozelius LG, et al. Genetic linkage of von Recklinghausen neurofibromatosis to the nerve growth factor receptor gene. Cell 1987;49:589-594

18. Rouleau G, Seizinger BR, Ozelius LG, et al. Genetic linkage analysis of bilateral acoustic neurofibromatosis to a DNA marker on chromosome 22. Nature 1987;329:246-248

19. Seizinger BR, Martuza RL, Gusella JF. Loss of genes on chromosome 22 in tumorigenesis of human acoustic neuroma. Nature 1986;322:644-647.

20. Rouleau GA, Merel P, Lutchman M, et al. Alteration in a new gene encoding a putative membrane-organizing protein causes neuro-fibromatosis type 2 . Nature 1993;363:515-521.

21. Troffater JA, MacCollin MM, Rutter JL, et al. A novel moesin-, ezrin-, radixin-like gene is a candidate for the neurofibromatosis 2 tumor suppressor. Cell 1993;72:791-800.

22. Evans DGR, Wallace A, Trueman L, Strachan T. Mosaicism in classical neurofibromatosis type 2: a common mechanism for sporadic disease in tumor prone syndromes? Am J Hum Genet 1998;63:727-736.

23. Legoix P, Sarkissian HD, Cazes L, et al. Molecular characterization of germline NF2 gene rearrangements. Genomics 2000;65:62-66.

24. Wallace AJ, Watson CJ, Oward E, Evans DG, Elles RG. Mutation scanning of the NF2 gene: an improved service based on meta-PCR/sequencing, dosage analysis, and loss of heterozygosity analysis. Genet Test 2004;8: $368-380$.
25. Kluwe L, Nygren AO, Errami A, et al. Screening for large mutations of the NF2 gene. Genes Chromosomes Cancer 2005;42:384-391.

26. Kluwe L, Freidrich RE, Tatagiba M, Mautner V. Presymptomatic diagnosis for children of sporadic neurofibromatosis 2 patients, a method based on tumor analysis. Genet Med 2002;4:27-30.

27. Baser ME. Neurofibromatosis $2(N F 2)$ mutation databases. Available at: http://archive.uwcm.ac.uk/uwcm/mg/hgmd0.html. http://www.hgmd.cf.ac.uk/nf2/. Accessed June 19, 2009

28. Baser ME; Contributors to the international NF2 mutation database. The distribution of constitutional and somatic mutations in the neurofibromatosis 2 gene. Hum Mutat 2006;27:297-306.

29. Ahronowitz I, Xin W, Kiely R, Sims K, Maccollin M, Nunes FP. Mutational spectrum of the NF2 gene: a meta-analysis of 12 years of research and diagnostic laboratory findings. Hum Mutat 2007;28:1-12.

30. Evans DGR, Ramsden RT, Shenton A, et al. What are the implications in individuals with unilateral vestibular schwannoma and other neurogenic tumors? J Neurosurg 2008;108:92-96

31. Mohyuddin A, Neary WJ, Wallace AJ, et al. Molecular genetic exclusion of NF2 in young patients diagnosed with a unilateral vestibular schwannoma. J Med Genet 2002;39:315-322.

32. Evans DGR, Ramsden RT, Shenton A, et al. Should NF2 mutation screening be undertaken in patients with an apparently isolated vestibular schwannoma? Clin Genet 2007;71:354-358

33. Parry DM, Eldridge R, Kaiser-Kupfer MI, Bouzas EA, Pikus A, Patronas N. Neurofibromatosis 2 (NF2): clinical characteristics of 63 affected individuals and clinical evidence for heterogeneity. Am J Med Genet 1994;52:450-451.

34. Mautner VF, Lindenau M, Baser ME, et al. The neuroimaging and clinical spectrum of neurofibromatosis 2. Neurosurgery 1996;38:880-885.

35. Baser ME, Friedman JM, Aeschilman D, et al. Predictors of the risk of mortality in neurofibromatosis 2. Am J Hum Genet 2002;71:715-723.

36. Ruggieri M, Iannetti P, Polizzi A, et al. Earliest clinical manifestations and natural history of neurofibromatosis type 2 (NF2) in childhood: a study of 24 patients. Neuropediatrics 2005;36:21-34.

37. Patronas NJ, Courcoutsakis N, Bromley CM, Katzman GL, MacCollin M, Parry DM. Intramedullary and spinal canal tumors in patients with neurofibromatosis 2: MR imaging findings and correlation with genotype. Radiology $2001 ; 218: 434-442$.

38. Dow G, Biggs N, Evans G, Gillespie J, Ramsden RT, King A. Spinal tumors in neurofibromatosis type 2 : is emerging knowledge of genotype predictive of natural history? J Neurosurg Spine 2005;2:574-579.

39. Kros J, de Greve K, van Tilborg A, et al. NF2 status of meningiomas is associated with tumour localization and histology. J Pathol 2001;194:367-372.

40. Evans DG, Watson C, King A, Wallace AJ, Baser ME. Multiple meningiomas: differential involvement of the NF2 gene in children and adults. $J$ Med Genet 2005;42:45-48.

41. Perry A, Giannini C, Raghavan R, et al. Aggressive phenotypic and genotypic features in pediatric and NF2-associated meningiomas: a clinicopathologic study of 53 cases. J Neuropathol Exp Neurol 2001;60:994-1003.

42. Ragge NK, Baser ME, Klein J, et al. Ocular abnormalities in neurofibromatosis 2. Am J Ophthalmol 1995;120:634-641.

43. Nguyen DQ, Chatterjee S, Bates R. Persistent hyperplastic primary vitreous in association with neurofibromatosis 2. J Pediatr Ophthalmol Strabismus 2005;42:247-249.

44. Sperfeld AD, Hein C, Schroder JM, Ludolph AC, Hanemann CO. Occurrence and characterization of peripheral nerve involvement in neurofibromatosis type 2. Brain 2002;125:996-1004.

45. Hagel C, Lindenau M, Lamszus K, Kluwe L, Stavrou D, Mautner VF, Polyneuropathy in neurofibromatosis 2: clinical findings, molecular genetics and neuropathological alterations in sural nerve biopsy specimens. Acta Neuropathol (Berl) 2002;104:179-187.

46. Cordeiro NJ, Gardner KR, Huson SM, et al. Renal vascular disease in neurofibromatosis type 2: association or coincidence? Dev Med Child Neurol 2006; $48: 58-59$.

47. Sobel RA, Wang Y. Vestibular (acoustic) schwannomas: histological features in neurofibromatosis 2 and in unilateral cases. J Neuropathol Exp Neurol 1993;52:106-113.

48. Baser ME, Kuramoto L, Joe H, et al. Genotype-phenotype correlations for nervous system tumors in neurofibromatosis 2: a population-based study. Am J Hum Genet 2004;75:231-239.

49. Parry DM, MacCollin M, Kaiser-Kupfer MI, et al. Germ-line mutations in the neurofibromatosis 2 gene: correlations with disease severity and retinal abnormalities. Am J Hum Genet 1996;59:529-539.

50. Ruttledge MH, Andermann AA, Phelan CM, et al. Type of mutation in the neurofibromatosis type 2 gene (NF2) frequently determines severity of disease. Am J Hum Genet 1996;59:331-342.

51. Kluwe L, Bayer S, Baser ME, et al. Identification of NF2 germ-line mutations and comparison with neurofibromatosis 2 phenotypes. [published erratum in Hum Genet 1997:99:292] Hum Genet 1996:98:534-538.

52. Evans DGR, Trueman L, Wallace A, Mason S, Strachan T. Genotype/phenotype correlations in type 2 neurofibromatosis: evidence for more severe disease with truncating mutations. $J$ Med Genet 1998;35:450-455. 
53. Baser ME, Kuramoto L, Woods RH, et al. The location of constitutional neurofibromatosis 2 (NF2) splice-site mutations is associated with the severity of NF2. J Med Genet 2005;42:540-546.

54. Evans DGR, Lye R, Neary W, et al. The probability of bilateral disease in individuals presenting with a unilateral vestibular schwannoma. J Neurol Neurosurg Psychiatry 1999;66:764-767.

55. Antinheimo J, Sankila R, Carpén O, Pukkala E, Sainio M, Jääskeläinen J. Population-based analysis of sporadic and type 2 neurofibromatosis-associated meningiomas and schwannomas. Neurology 2000;54:71-76.

56. Szijan I, Rochefort D, Bruder C, et al. NF2 tumor suppressor gene: a comprehensive and efficient detection of somatic mutations by denaturing HPLC and microarray-CGH. Neuromolecular Med 2003;3:41-52.

57. Hulsebos TJ, Plomp AS, Wolterman RA, Robanus-Maandag EC, Baas F, Wesseling P. Germline mutation of INI1/SMARCB1 in familial schwannomatosis. Am J Hum Genet 2007;80:805-810.

58. Hadfield KD, Newman WG, Bowers NL, et al. Molecular characterisation of SMARCB1 and NF2 in familial and sporadic schwannomatosis. $J$ Med Genet 2008;45:332-339.

59. MacCollin M, Chiocca EA, Evans DG, et al. Diagnostic criteria for schwannomatosis. Neurology 2005;64:1838-1845.

60. Murray A, Hughes TAT, Neal JW, Howard E, Evans DGR, Harper PS. A case of multiple cutaneous schwannomas; schwannomatosis or neurofibromatosis type 2? J Neurol Neurosurg Psychiatry 2006;77:269-271.

61. Sestini R, Bacci C, Provenzano A, Genuardi M, Papi L. Evidence of a four-hit mechanism involving SMARCB1 and NF2 in schwannomatosisassociated schwannomas. Hum Mutat 2008;29:227-231.

62. Boyd C, Smith MJ, Kluwe L, Balogh A, Maccollin M, Plotkin SR. Alterations in the SMARCB1 (INI1) tumor suppressor gene in familial schwannomatosis. Clin Genet 2008;74:358-366.

63. Maxwell M, Shih SD, Galanopoulos T, Hedley-Whyte ET, Cosgrove GR. Familial meningioma: analysis of expression of neurofibromatosis 2 protein merlin. Report of two cases. J Neurosurg 1998;88:562-569.

64. Pulst SM, Rouleau GA, Marineau C, Fain P, Sieb JP. Familial meningioma is not allelic to neurofibromatosis 2. Neurology 1993;43:2096-2098.

65. Lomas J, Bello MJ, Arjona D, et al. Genetic and epigenetic alteration of the NF2 gene in sporadic meningiomas. Genes Chromosomes Cancer 2005;42: 314-319.

66. Masuda A, Fisher LM, Oppenheimer ML, Iqbal Z, Slattery WH. Hearing changes after diagnosis in neurofibromatosis type 2. Otol Neurotol 2004;25: $150-154$.

67. Slattery WH III, Fisher LM, Iqbal Z, Oppenhiemer M. Vestibular schwannoma growth rates in neurofibromatosis type 2 natural history consortium subjects. Otol Neurotol 2004;25:811-817.

68. Rowe JG, Radatz M, Walton L, Kemeny AA. Stereotactic radiosurgery for type 2 neurofibromatosis acoustic neuromas: patient selection and tumour size. Stereotact Funct Neurosurg 2002;79:107-116.

69. Rowe JG, Radatz MW, Walton L, Soanes T, Rodgers J, Kemeny AA Clinical experience with gamma knife stereotactic radiosurgery in the management of vestibular schwannomas secondary to type 2 neurofibromatosis. J Neurol Neurosurg Psychiatry 2003;74:1288-1293.
70. Baser ME, Evans DGR, Jackler RK, Sujansky E, Rubenstein A. Malignant peripheral nerve sheath tumors, radiotherapy, and neurofibromatosis $2 . \mathrm{BrJ}$ Cancer 2000;82:998.

71. Evans DGR, Birch JM, Ramsden RT, Sharif S, Baser ME. Malignant transformation and new primary tumours after therapeutic radiation for benign disease: substantial risks in certain tumour-prone syndromes. $J$ Med Genet 2006;43:289-294

72. Balasubramaniam A, Shannon P, Hodaie M, Laperriere N, Michaels H, Guha A. Glioblastoma multiforme after stereotactic radiotherapy for acoustic neuroma: case report and review of the literature. Neuro Oncol 2007;9: 447-453.

73. Sakai T, Vallejo MC, Shannon KT. A parturient with neurofibromatosis type 2: anesthetic and obstetric considerations for delivery. Int J Obstet Anesth 2005; $14: 332-335$

74. Spiegel JE, Hapgood A, Hess PE. Epidural anesthesia in a parturient with neurofibromatosis type 2 undergoing cesarean section. Int $J$ Obstet Anesth $2005 ; 14: 336-339$.

75. Feucht M, Griffiths B, Niemüller I, Haase W, Richard G, Mautner VF. Neurofibromatosis 2 leads to higher incidence of strabismological and neuro-ophthalmological disorders. Acta Ophthalmol 2008;86:882-886.

76. Hirokawa Y, Tikoo A, Huynh J, et al. A clue to the therapy of neurofibromatosis type 2: NF2/merlin is a PAK1 inhibitor. Cancer $J$ 2004;10:20-26.

77. Hanemann CO. Magic but treatable? Tumours due to loss of merlin. Brain 2008;131(Pt 3):606-615

78. Evans DG, Kalamarides M, Hunter-Schaedle $\mathrm{K}$, et al Consensus recommendations to accelerate clinical trials for neurofibromatosis type 2 [published online ahead of print August 15, 2009]. Clin Cancer Res doi:10.1158/ 1078-0432.

79. Plotkin SR, Singh MA, O’Donnell CC, Harris GJ, McClatchey AI, Halpin C. Audiologic and radiographic response of NF2-related vestibular schwannoma to erlotinib therapy. Nat Clin Pract Oncol 2008;5:487-491.

80. Ammoun S, Flaiz C, Ristic N, Schuldt J, Hanemann CO. Dissecting and targeting the growth factor-dependent and growth factor-independent extracellular signal-regulated kinase pathway in human schwannoma. Cancer Res 2008; 68:5236-5245.

81. Warren C, James LA, Varley JM, Ramsden RT, Evans DG. Identifying recurrent regions of chromosome loss and gain in 76 vestibular schwannomas using comparative genomic hybridisation (CGH). J Med Genet 2003; 40:802-806.

82. Kino $\mathrm{T}$, Takeshima $\mathrm{H}$, Nakao $\mathrm{M}$, et al. Identification of the cis-acting region in the NF2 gene promoter as a potential target for mutation and methylationdependent silencing in schwannoma. Genes Cells 2001;6:441-454.

83. Gonzalez-Gomez P, Bello MJ, Alonso ME, et al. CpG island methylation in sporadic and neurofibromatosis type 2-associated schwannomas. Clin Cancer Res 2003;9:5601-5606.

84. Evans DG, Maher ER, Baser ME. Age-related shift in the mutation spectra of germline and somatic NF2 mutations: hypothetical role of DNA repair mechanisms. J Med Genet 2005;42:630-632.

85. McClatchey AI, Giovannini M. Membrane organization and tumorigenesisthe NF2 tumor suppressor, merlin. Genes Dev 2005;19:2265-2277. 